Vol 10, Issue 2, 2017

\title{
EDIBLE VACCINES: AN ADVANCEMENT IN ORAL IMMUNIZATION
}

\author{
RAJASHREE HIRLEKAR*, SRINIVAS BHAIRY \\ Department of Pharmaceutics, Vivekanand Education Society's College of Pharmacy, Hashu Advani Memorial Complex, Behind Collector \\ Colony, Chembur (E), Mumbai, Maharashtra, India. E-mail: rajashree.hirlekar@ves.ac.in
}

Received: 22 October 2016, Revised and Accepted: 22 November 2016

ABSTRACT

Vaccines represent a useful contribution to the branch of biotechnology as they supply protection against various diseases. However, the major hurdle to oral immunization is the digestion of macromolecule antigenic protein within the stomach due to extremely acidic $\mathrm{pH}$. To address this issue, scientist Arntzen developed the theory of edible vaccines (EVs). EVs are developed using the genetic engineering technology in which the appropriate genes are introduced into the plants using various methods. This genetically modified plant then produces the encoded protein which acts as a vaccine. Owing to its low cost, it will be affordable for developing countries like India. EVs are developed to treat various diseases such as malaria, measles, hepatitis B, stopping autoimmunity in type-1 diabetes, cholera, enterotoxigenic Escherichia coli (ETEC), HIV, and anthrax. This review comprises mechanism of action, methods of development, candidate plants, applications, and clinical trials of EVs.

Keywords: Edible vaccines, Antigens, Oral immunization, Immunity.

(C) 2017 The Authors. Published by Innovare Academic Sciences Pvt Ltd. This is an open access article under the CC BY license (http://creativecommons. org/licenses/by/4. 0/) DOI: http://dx.doi.org/10.22159/ajpcr.2017.v10i2.15825

\section{INTRODUCTION}

\section{Vaccines}

Vaccines represent a useful contribution to the branch of biotechnology as they supply protection against varied diseases. All organisms are vulnerable to one or more forms of infectious and noninfectious diseases throughout their life. To prevent these infection researchers discovered plant-based vaccine which is an immune-biological substance, used for specific protection against both infectious and noninfectious diseases. The process of distributing and administrating vaccines is referred to as vaccination and vaccination is a form of immunization [1-4]. Typical vaccines consist of killed or live/attenuated disease-causing organisms. Very few patients show a recurrence of the disease for which they have been vaccinated, thereby cutting down the cost of expensive treatment procedures [5]. Immunization is a two-centuryold science of prophylaxis. Edward Jenner is regarded as the father of immunization as he was the first to study that inoculation of cowpox virus prevents small pox in human. After this discovery, the cowpox vaccination came into clinical use worldwide in the $19^{\text {th }}$ century. The science of immunization peaked to new heights in late $19^{\text {th }}$ century to early $20^{\text {th }}$ century and during World War II [6-10].

Administration of vaccines involves activation of the immune system to prepare it for the event of an invasion from a particular pathogen for which the immune system has been primed. Vaccines are used for active immunization as a prophylactic measure against some infectious diseases. They provide partial or complete protection for months or years. Vaccines can be given via various routes of administration, including oral, nasal, and parenteral routes such as intramuscular (IM), subcutaneous (SC), and intradermal (ID). It is well documented that the route of administration can impact the type of immune response. The majority of commercial vaccines are administered by IM or SC routes. The emergence of tissue culture techniques revolutionized the immunization approaches. A number of new vaccines with different approaches - such as live/attenuated bacterial or viral vaccines, killed bacterial suspension, toxins produced by bacterial toxoids, and rickettsial suspension - have been developed [10].

Difficulties in traditional vaccine systems

The major limitations with conventional vaccines are their storage, transport under strictly controlled conditions (dependence on cold chain system), and possibility of adverse reactions either due to reactions inherent to inoculation or because of faulty techniques.

Criteria for standard oral vaccine system:

i. Desired antigens should be present in adequate quantities

ii. Stability of expressed antigen at room temperature for a long time

iii. Protective immunity must be induced by the vaccine

iv. Must withstand degradation by enzymes in the stomach $[4,11,12]$.

The evolution of plant-derived vaccine technology

Since the conventional vaccines have many limitations, this led to the search for new vaccines which are having flexibility in administration, storage, transportation and ultimately cost-effective. Hence, there is a plenty of scope in developing plant-derived immunizing agent. Scientist's counsel that plants and plant viruses are genetically built to provide vaccines against diseases. Consequently, some study shows plant-derived vaccines considerably increase availability of vaccines in places wherever maintenance of cold conditions is tough. Developments in transgenic research have created the production of transgenic plants expressing antigenic proteins which are induced by plant transgenic vectors. This will help to produce special vaccines with high anti-disease ability $[13,14]$.

During the last decade, different types of efficient plant-based expression systems have been studied, and more than 100 different types of transgenic proteins including plant-derived vaccine antigens have been successfully expressed in different types of plant tissues. Positive effects of edible vaccines (EVs) include the decrease in potential hazards such as toxic compounds, responses to allergy, and risk of attenuated strains reverting to pathogenic strains. The EVs have several functions for either individual animals or humans by providing long lasting immunity without risk of relapse reaction and faulty techniques; there exists a lack of information regarding their production and mechanism of action [15].

\section{Concept of EVs}

The concept of EVs was developed by Arntzen in the 1990s. The earliest demonstration of an EV was the expression of a surface antigen from the bacteria Streptococcus mutans in tobacco. As this bacteria causes 
dental caries, it had been suggested that the stimulation of a mucosal immune response would stop the bacteria from colonizing the teeth and therefore protect against tooth decay. Vaccine antigens can be delivered orally by administration of transgenic edible parts which are developed using the methods of molecular biology. The genes of interest can be introduced into plants where they are expressed in the plant tissues including the edible components. This process is known as "transformation" and the genetically modified plants are referred as "transgenic plants." These genes encode protective vaccine antigens from viral, bacterial and parasitic pathogens that cause disease in humans and animals. The vaccine can be delivered by intake of the edible part of the genetically modified plant, or the high-yield production of refined protein for oral delivery EVs are like unit preparations as they are built to contain antigens, however, bear no genes that might change whole pathogens to cause harmful effects to humans (Fig. 1). Thus, they have no means of creating an infection, assuring its safety, particularly in immune-compromised patients. In comparison to traditional vaccines, EVs have a lot of compliance, especially in children, and due to oral administration, it eliminates the necessity of trained medical personnel. Their production is very economical and can be easily scaled up. They are less expensive, heatstable, do not require cold temperature maintenance, can be stored near the site of use. They do not require syringes and needles, exhibit good genetic stability, can be grown regionally using standard methods and do not require capital-intensive pharmaceutical manufacturing facilities [16-20].

\section{Properties of an ideal vaccine}

i. It should not be toxic or pathogenic, i.e., it should be safe

ii. It should have very low levels of side effects in normal individuals

iii. It should not cause problems in individuals with impaired immune system

iv. It should produce long-lasting humoral and cellular immunities

v. The vaccination technique should be simple

vi. The vaccine should be less expensive

vii. Contamination of the environment should not happen

viii. It should be effective and affordable [9,21,22]

\section{Advantages and disadvantages of EVs}

\section{Advantages}

i. They can be mass-produced. Hence, they are economical

ii. They can be administered by eating the plant/part of the plant. Hence, the processing and purification steps can be eliminated

iii. They can be stored at normal room temperature. Extensive cold storage conditions are not required

iv. The process of transportation and distribution can be eliminated, if the local/native crop of a particular area is engineered to produce the vaccine v. They trigger the body's first line of defense (immunity at the mucosal surfaces).

\section{Disadvantages}

i. Selection of plant with stable antigen production could be a difficult task, time-consuming, and expensive

ii. Lack of knowledge regarding plant biotechnology which leads to negative public opinions, stringent laws, and debates regarding intellectual property discourage pharmaceutical business investments in EVs

iii. Possibility for hypersensitive reaction, development of oral tolerance to vaccines and also difficulty in the administration of the standard dose are additional limitations $[23,24]$.

\section{Mechanism of action}

The major drawback to oral vaccination is the digestion of macromolecule antigenic protein within the stomach due to extremely acidic pH. Edible parts of plants can be fed directly, as the outer robust wall of plant cells act to safeguard the antigens against attack by enzymes and secretions in the stomach by internal organs. This is described as bio-encapsulation. The plant cytomembrane breaks within the intestine to release the antigens [25].

The antigens are released taken up by $\mathrm{M}$ cells (specialized epithelial cells present in GIT with high capacity of transcytosis of a wide range of microbes and macromolecules) in the intestinal lining that overlie Peyer's patches (PPs). PPs (a group of lymphatic nodules also termed as aggregated lymphatic follicles) are an enriched source of secretory immunoglobulin (Ig) A which generate plasma cells and have a potential to populate mucosal tissue, and serve as mucosal immune effectors sites. The breakdown of EVs near PP causes antigenic stimulation of follicles and development of the germinal center. The antigen penetrates through these follicles into the epithelium of intestine, and these antigens accumulate within organized lymphoid tissues [26].

The immune system composed of various constituents such as B-cell T-cells, and macrophages is accumulated in lymphoid follicles. M-cells expressing class II Muco-histo-compatibility complex molecules and antigens transported across the mucous membrane by M-cells can activate B-cells within these lymphoid follicles. The activated B-cells leave the lymphoid follicles and migrate to diffuse mucosal-associated lymphoid tissue to differentiate into plasma cells that secrete serum IgG, IgE, local IgA and generate memory cells, which would neutralize the attack by the original infectious agent present in the body. Administration of EVs to mothers might be successful in immunizing the fetus-in-utero by trans-placental transport of maternal antibodies or the infant through breast milk [27-30].

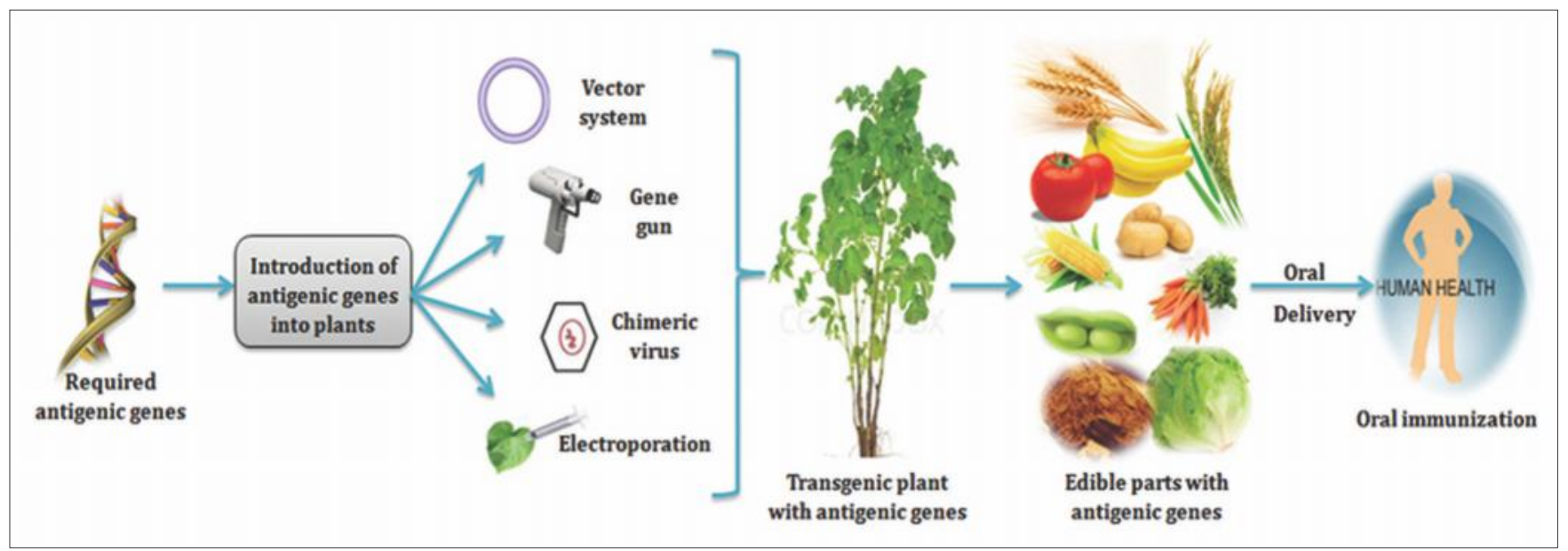

Fig. 1: Concept/graphical abstract of edible vaccines 


\section{METHODS FOR TRANSFORMATION OF DNA/GENE INTO PLANTS}

It has been reported that the methods mentioned below are used for development of EVs. Fig. 2 depicts various methods for transformation of desired DNA/gene into plants.

Plasmid/vector carrier system: Agrobacterium tumifaciens method

One way of generating EVs depends on the microorganism species to deliver into plant cells the genetic blueprints for an infectious agent or microorganism "antigens" proteins that elicit a targeted immunologic response within the recipient [13]. A. tumifaciens is present in soil which is employed to transfer a little phase of DNA into plant ordination and this method is termed transformation. The whole plant is regenerated from an individual plant cell. It has been reported that genes which are expressed successfully in experimental model plants, when given orally to animals, generate serum antibodies. Vegetable pathogens, A. tumefaciens and Agrobacterium rhizogenes, have potential to integrate their DNA (T-DNA) into the infected cell's nuclear genome. The introduction of exogenous genes into the adequately

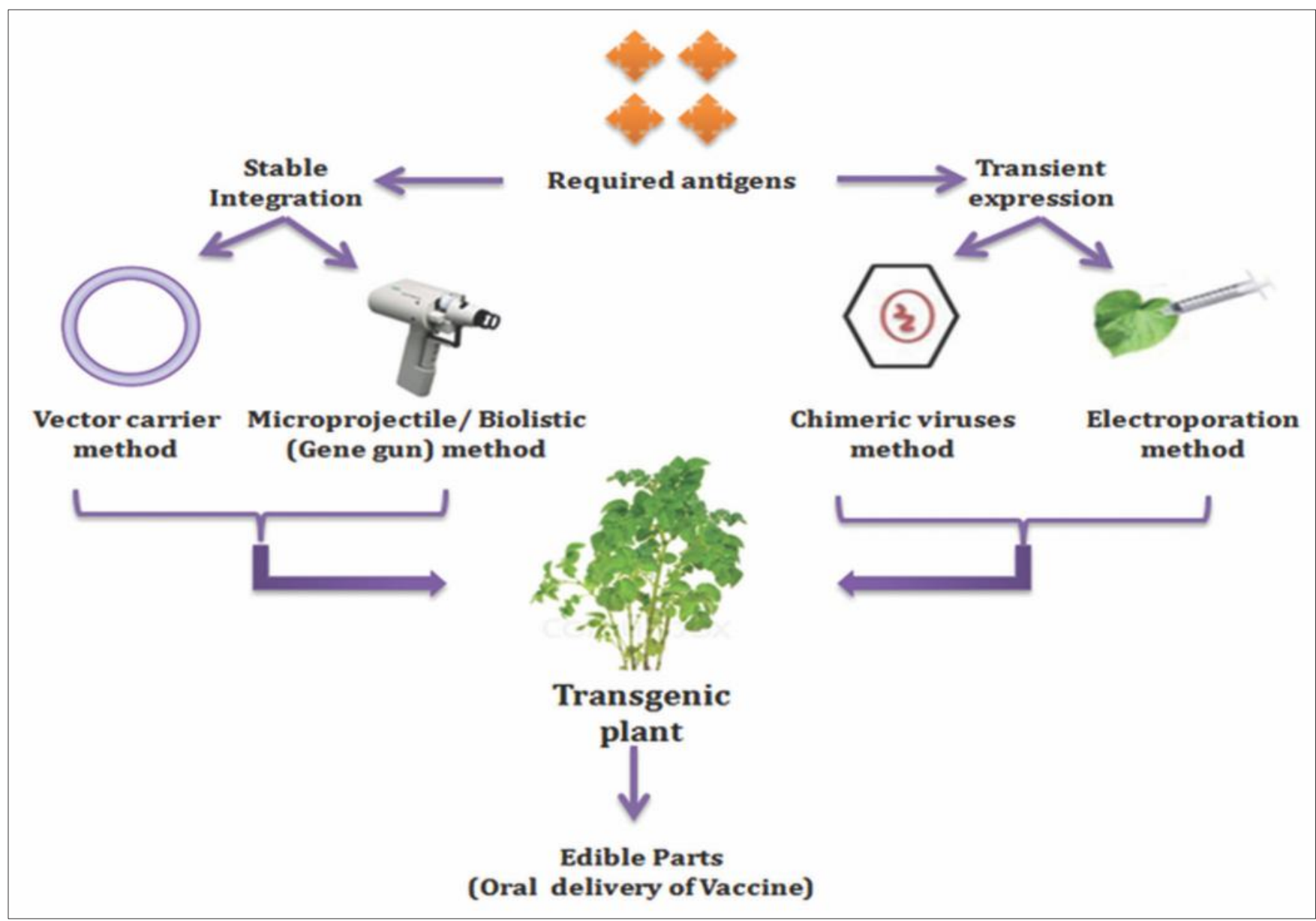

Fig. 2: Schematic diagram showing various methods of production of plant based edible vaccines

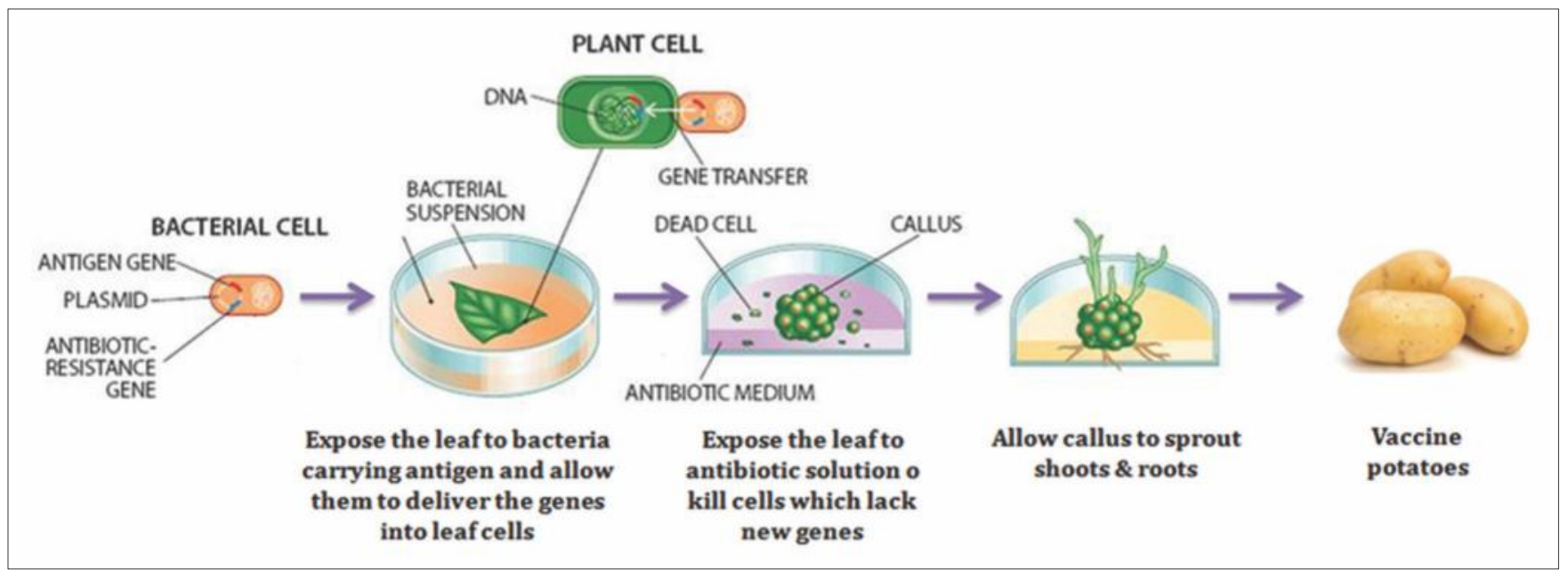

Fig. 3: Schematic representation of plasmid/vector carrier system 
modified T-DNA of Agrobacterium cells and following infection of a vegetable tissue led to the study of gene's stable integration in the plant's genome and production of a transgenic protein which acts as an EV (Fig. 3) [31-34].

Micro projectile bombardment (biolistics)/gene gun method The gene containing DNA-coated metal (e.g., gold and tungsten) particles are fired at the plant cells by means of the gene gun. These plant cells uptakes the DNA then permitted to grow in new plants and are cloned to supply a large amount of genetically similar crop. This technique is more often suitable to deliver DNA into cells of the plant that makes the transfer of genes independent of regeneration ability of the species. However, the limitation is that the technique is not economical because of particle gun device $[4,6,35]$.

\section{Chimeric virus method}

Plant viruses are genetically modified to carry the desired genes and used to infect their natural hosts such as the edible plants where the cloned genes are expressed to varying degrees in different edible parts of the plant (Fig. 4). Certain viruses can be redesigned to express fragments of antigenic proteins on their surfaces such as cowpea mosaic virus, alfalfa mosaic virus, tobacco mosaic virus, cauliflower mosaic virus (CaMV), potato virus, and tomato bushy stunt virus $[4,36,37]$.

\section{Electroporation method}

The introduction of DNA into cells is done by exposing the cells for a brief period to high voltage electrical pulse that is assumed to induce transient pores within the plasmalemma (a thin layer of tissue that covers surface). The cell wall acts an efficient barrier to DNA. Hence, it has to be weakened by enzymatic treatment thus permit the entry of DNA into the cell $[4,21]$.

\section{CANDIDATES FOR EVs}

Edible parts of different species of plants plant, such as the grains or fruits, are utilized for the expression of the desired antigen of interest. Cereals like rice and maize, fruits like banana, leaves of many plants (tobacco, alfalfa, peanut leaves), tubers like potatoes, tomatoes, soybean seeds, cowpea, pea, carrot, peanut, and lettuce have been extensively used for high levels of antigenic protein expression. The factors to be considered while selecting the vehicle for the vaccine: Plant should be hardy, it should be palatable and well relished, it should be indigenous, easily available and transformation can be done easily [38-40].

Several things have to be considered when selecting an expression host, like gene of interest to be expressed in leaves or in dry tissues like cereals based on the final part to be used for the vaccination purpose. The advantages of using grains as an expression host are many like it can store proteins for many years, is cost-effective, large volumes of desired products can be produced in short span of time and can be easily harvested and processed. The generally used plant for expression of a protein is tobacco because of its transforming ability. The ultimate goal of using transgenic plants as production systems for animal and human vaccine antigens is to facilitate easier delivery of immunizing antigen so that mass immunization can be achieved against infectious diseases [4,41-43].

\section{Banana}

Bananas are sterile so the genes do not pass from one banana to another which is the main reason why bananas are a good choice for an EV. The tropical climate is suitable for growing bananas. Most thirdworld countries are found in this climate. It does not need cooking. Proteins are not destroyed even if cooked and it can be eaten as raw. It is inexpensive, can be grown widely in developing countries, grow quickly and have the high vitamin A content which boosts immune response. Disadvantages are tree take 2-3 years to mature, transformed tree take about 12 months to bear fruits, spoils rapidly after ripening [44].

\section{Rice}

An EV using genetically altered rice is used in cholera treatment Cholera vaccine exists but provides short-lived protection and requires refrigeration. It has been reported that a strain of rice can serve as a vaccine and last for more than a year and a half at normal room temperature. It is used as pediatric food because of the low level of allergenic potential but grows slowly and requires specialized glasshouse condition [4].

\section{Maize}

Maize plants generate a protein that is used to develop the hepatitis $B$ virus vaccine. It is cheaper and does not need to be refrigerated. A major disadvantage of this vaccine is to be cooked for use which causes degradation of proteins [14].

\section{Potato}

A potato based vaccine used to combat the Norwalk virus (stomach virus), which is spread by contaminated water and food and causes severe abdominal pain and diarrhea. Potato has been also served as a vehicle for diabetes-related proteins, the vaccine against a strain of Escherichia coli, cholera vaccine. A potato based vaccine has advantages such as safely stimulating antibodies, affordable, and stored for a prolonged period without refrigeration. The major limitation is it needs cooking which can denature antigen and decrease immunogenicity $[4,44]$.

\section{Tomato}

It has been reported that tomato can be served as a vector to develop the vaccines against anthrax, rabies and HIV/AIDS. It has merits such as grows quickly, cultivated broadly, heat-stable, and high vitamin A composition may boost immune response. Antigen-containing powders can be filled into capsules and with no requirement of special facilities for storage and transportation. However, it has demerit as spoils easily hence cannot be stored for over a long period [45].

\section{Tobacco}

Human papilloma viruses (HPV) are the causative agent for cervical cancer and also involved in skin, head, and neck tumors. More than 150 distinct classes of HPV are known. The most commonly found HPVs in cervical carcinomas are HPV 16 and 18. Virus proteins E6 and E7 are known as oncoproteins; these are the promising target for the development of HPV-associate tumors. It has been reported that, when HPV16 E7 protein was introduced into the cytoplasm tobacco

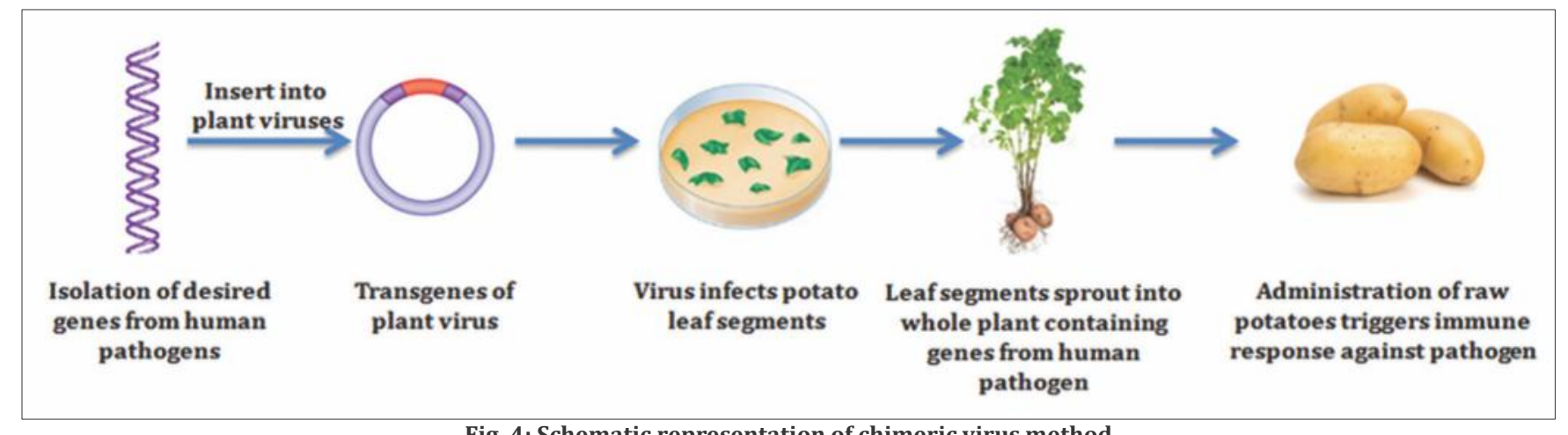

Fig. 4: Schematic representation of chimeric virus method 
(Nicotiana benthamiana) plants, the E7 production level were of $15 \mu \mathrm{g}$ of protein/g of fresh leaf) [46]. Tobacco plants are a good model for evaluating recombinant proteins and can be harvested a number of times in a year. However, due to the composition of a high level of toxic alkaloids, it causes more toxicity [47-49].

\section{Miscellaneous candidates}

Some other plants which can also be served for vaccine delivery are lettuce (fast-growing but, spoils readily), soybean (direct consumption, can be harvested a number of times in a year. but, spoils readily), and wheat (large number of seeds help in an increased harvest but need cooking) [47-49]. Table 1 enlists the various vaccines under clinical development.

\section{STABILITY AND PROCESSING OF PLANT-DERIVED VACCINES}

Reliable strategies are required to quantify plant-derived antigens and for their stability. Lee et al. reported that 50 fusion proteins containing the Mannheimia haemolytica A1 leukotoxin were harvested using clover plants as an expressing system and allowed to dry at temperature ambient humidity for 1 to 4 days. After 3 days, 20\% of its initial fresh weight of the clover tissue was retained but no significant degradation of the fusion protein was observed. Hence, the fusion protein did not require cold storage conditions for stability. When the clover-expressed fusion protein was injected into rabbits induced an immune response that recognized and neutralized the native antigen in modified neutral red cytotoxicity assays [33]

Smith et al. performed a more comprehensive stability study. The quantification of antigenically reactive $\mathrm{Hbs}$ Ags was found to be strongly dependent on the ratio of detergent: Cell concentration. A $1-20 \% \mathrm{w} / \mathrm{v}$ sodium ascorbate concentration improved the measured levels of monoclonal-reactive antigen 4 to 12 -fold. Antigen stability was influenced by detergent in cell lysates stored at $48^{\circ} \mathrm{C}$. Under optimum conditions, stability was maintained for at least 1 month; proteolytic degradation was observed when stored with excess detergent concentration. Proteolysis was counteracted by the addition of skimmed milk or its protein component; this stabilizes the antigen for up to 2 months [52].

Castanon et al. investigated the minimal processing of a potato-derived rabbit hemorrhagic disease virus (RHDV) vaccine consisting of the VP60 gene. Harvested potatoes were peeled, cut into pieces, lyophilized, powdered, stored and used in trials within 3 months of collection. Rabbits were primed SC and boosted IM with extracts made from the potato powder. The rabbits immunized with the transgenic potato induced specific antibody responses and were protected against RHDV [53,54].

\section{REGULATORY ASPECTS/ISSUES}

It has to be set whether or not EVs would be regulated underneath food, medicine or agricultural product. Further, it is undecided that licensing shall be needed for the antigenic protein or genetically built fruit or transgenic seeds. The transgenic plants need greenhouse segregation and separate bodies that make sure that such plants are not rereleasing the antigenic proteins in the environment by any means. Transgenes may spread by sucking insects, pollen and transfer to soil microbes during plant wounding or breakdown of roots and may pollute surface and ground water. Ethical considerations usually restrict clinical trials from directly assessing protection in humans [26]

\section{APPLICATIONS OF EVs}

Malaria

Several strategies have been tested to combat malaria and innumerable attempts have been made to launch a malaria vaccine [55]. Three antigens are under investigation for the development of EVs, merozoite surface protein (MSP) 4 and MSP 5 from Plasmodium falciparum, and MSP4/5 from Plasmodium yoelii. Wang et al. have reported that oral administration of recombinant MSP 4, MSP 4/5 and MSP1, coadministered with cholera toxin B (CTB) as a mucosal adjuvant to a mice, induced antibody responses effective against the blood-stage parasite. It has been suggested that antigen expression level in plants is low, this requires the administration of a large quantity of plant material to achieve the desired immunity. Moreover, due to the high degree of antigen anticipated to be necessary, it is likely that strong adjuvant will also be required $[6,56,57]$.

\section{Measles}

The vaccine currently in use produces $95 \%$ seroconversion (It is the period of time during which a specific antibody develops and becomes detectable in blood) in individuals who are over the age of 18 months at the time of vaccination. Measles live-attenuated vaccine does not induce oral immunization effect and destroyed by heat. Hence, refrigeration is the prerequisite for its storage. Maternal antibodies also reduce the immunization response of vaccine. Measles virus hemagglutinin (MV-H) from edmonston strain antigen was selected for the development of an $\mathrm{EV}$, which can be transformed into tobacco plant by plasmid/vector. It was also reported that mice fed with tobacco expressing MV-H could attain antibody titers 5 times the level considered protective for humans and they also demonstrated secretory IgA in their feces [19,58-60].

Oral administration of MV-H encapsulated transgenic plant extract induced serum antibodies, which neutralized the wild-type MV and retained its immunogenicity. Results indicated that IgA antibodies were found in the fecal samples of animals immunized orally with plant derived MV-H. It has also been studied that transgenic carrot plant could be used to deliver viral antigens for the development of measles vaccine [6].

\section{Hepatitis B}

It was reported that the ingestion of single potato was able to provide the amount of HBs Ag needed for one dose. Levels of specific antibodies

Table 1: Plant-origin pharmaceutical proteins developed clinically with designated medical applications [50,51]

Product

Vaccine containing E. coli heat labile toxin

Norwalk virus vaccine

Hepatitis B surface antigens (HBsAg) IgG

(hepatitis B virus)

Rabies virus glycoprotien/nucleoprtien antibodies

Single chain viable region vaccine

Avicidin

Gastric lipase

Lactoferrin

Human intrinsic factor
Plant host

Potato, maize

Potato, tobacco, tomato

Potato, banana, tobacco,

cherry, tomato, lettuce

Spinach, tobacco

Tobacco

Maize

Maize

Maize

Arabidopsis
Indication

Diarrhea

Sickness and diarrhea

Hepatitis B

Rabies

Non-hodgkins lymphoma

Colorectal cancer

Cystic fibrosis, pancreatitis

Gastrointestinal infections

Vitamin B12 deficiency
Route of administration

Oral

Oral

Oral

Oral

Oral

Oral

Oral

Oral

Oral
Product stage development

Phase 1

Phase 1

Phase 1

Phase 1

Phase- 1 trials

Withdrawn from Phase-Il

trials

Phase-Il

Phase-II

Phase-II 
significantly exceeded the protective level of $10 \mathrm{mIU} / \mathrm{mL}$ in humans. When cloned into CaMv, plasmid HBsAg subtype ayw showed higher expression in roots as compared to leaf tissue of the genetically modified potato. Tomatoes expressing HBsAg are being grown in guarded greenhouses. It was demonstrated that 30 tomato plants were able to provide enough antigens for 4,000 vaccine doses $[61,62]$.

\section{Stopping autoimmunity}

Ingesting autoantigens (proteins derived from uninfected tissue in a treated individual), or "self-antigens," might suppress autoimmunity in type I diabetes. Type I diabetes progresses silently for a time. Eventually, though, the loss of beta cells causes a drastic shortage of insulin, which results in high blood sugar levels. Insulin injections can be used to control diabetes, but they are by no means a cure. It has been reported that the plant-based diabetes vaccines such as potatoes containing insulin or glutamic acid decarboxylase linked to the innocuous B subunit of the Vibrio cholera toxin (to enhance uptake of the antigens by M cells) when administered to a diabetic mouse helped to suppress the immune attack and to prevent or delay the onset of high blood sugar $[30,63]$.

\section{Cholera}

Genetically modified potatoes expressing СTB were found to produce both serum and secretory antibodies when fed to mice. Since people eat only cooked potatoes, the effect of boiling on the properties of CTB expressed in transgenic potatoes was examined. It was evidenced that, over half of the vaccine protein survived in its biologically active form even after boiling for five minutes and this proves that cooking does not always inactivate EVs [64-66]

\section{Enterotoxicogenic E. coli (ETEC)}

It has been reported that when 11 volunteers were fed raw genetically modified potatoes containing heat-labile enterotoxin B, 10 (91\%) of these volunteers generated neutralizing antibodies and 6 (55\%) generated a mucosal response against ETEC [67]

\section{Norwalk virus}

Nineteen (95\%) out of 20 people when administered transgenic potato expressing Norwalk virus antigen developed seroconversion. Genetically engineered bananas and powdered tomatoes expressing Norwalk virus are under development phase to combat Norwalk virus [67].

\section{HIV}

Genetically modified tomatoes were developed by injecting two HIV protein genes along with promoters such as CaMV with a needle and the expressed protein was demonstrable by polymerase chain reaction in different parts of the plant, including the ripe fruit, as well as in the second- generation plant. Recently, spinach has been successfully inoculated for Tat protein expression cloned into TMV. Each gram of leaf tissue of spinach was able to contain up to 300-500 mg of Tat antigen. Higher antibody titers were observed than the controls when mice were fed with this spinach $[68,69]$

\section{Anthrax}

Tobacco leaves bombarded with pag gene (anthrax protective antigen [PA]) using a gene gun could express a protein structurally identical to the major protein present in existing vaccine. Billions of units of anthrax antigen could be produced. This vaccine was lacking edema factor and lethal factor which are responsible for potential toxic side effects. The same anthrax antigen is now being put in tomato plants. It was also suggested that transgenic spinach might be a safer vaccine upon inoculating it with TMV-expressing PA [70].

\section{FUTURE DIRECTIONS}

The future of EVs depends on following factors:

- Socio-cultural acceptability of genetically changed plants,

- Stability of genetically modified varieties and

- Proper segregation of transgenic plants, prevention of environment contamination and prevention of potent side effects of transgenes as allergens.
EVs can be safe and effective modes of immunization and are better as compared to the traditional vaccines when mass production, distribution, and delivery are concerned. Therefore, there is a need for the development of a cost-effective, efficient and safe delivery.

\section{CONCLUSION}

EVs are the milestone in the branch of biotechnology for developing inexpensive vaccines that are particularly useful in immunizing people in developing countries, where high cost, transportation and the need for cold storage conditions, are hampering effective vaccination programs. Edible plant-based vaccine may lead to a future of safer and more effective immunization. The expectation is that EVs may be fully grown in many of the developing countries where they would actually be used.

\section{REFERENCES}

1. Charmi PS, Manisha NT, Urmila DV, Vishwash JJ. Edible vaccine: A better way for immunization. Int J Curr Pharm Res 2011;3:53-6.

2. Morr TS, Gomez LM, Palmer KE. Edible vaccines: A concept comes of age. Trends Microbiol 1998;6:449-53.

3. Daniell H, Streatfield SJ, Wycoff K. Medical molecular farming: Production of antibodies, biopharmaceuticals and edible vaccines in plants. Trends Plant Sci 2001;6(5):219-26.

4. Hafiz E, Eyob H. Review on edible vaccine. Acad J Nutr 2015;4:40-9.

5. Hudu SA, Shinkafi SH, Shuaibu U. An overview of recombinant vaccine technology, adjuvants and vaccine delivery methods. Int J Pharm Pharm Sci 2016;8:19-24.

6. Neeraj M, Prem NG, Kapil K, Amit KG, Suresh PV. Edible vaccines: A new approach to oral immunization. Indian J Biotechnol 2008;7:283-94

7. Streatfield SJ. Plant-based vaccines for animal health. Rev Sci Tech 2005;24(1):189-99.

8. Swamy KT, Reddy NS, Rao S. Green revolution vaccines, edible vaccines. Afr J Biotechnol 2003:2:679-83.

9. Swarnali D, Rohitas D. Advances in vaccination: A review. Int J App Pharm 2009;1:1-21.

10. Singh RP, Singh P, Mishra V, Prabakaran D, Vyas SP. Vesicular systems for non-invasive topical immunization: Rationale and prospects. Indian J Pharmacol 2002;34:301-10.

11. Goldblatt D, Ramsay M. Immunization in domestic animal. Oxford Text Book of Medicine. 4 $^{\text {th }}$ ed. United Kingdom: Oxford University Press; 2003.

12. Levine MM. Enteric infections and the vaccines to counter them: Future directions. Natl Med 2006;24(18):3865-73

13. Yoshida T, Kimura E, Koike S, Nojima J, Futai E, Sasagawa N, et al. Transgenic rice expressing amyloid B-peptide for oral immunization. Int J Biol Sci 2011;7:301-7.

14. Arakawa T, Chong D, Langridge W. Transgenic plants for the production of edible vaccine and antibodies for immunotherapy. Nat Biotechnol 1998;16:292-7.

15. Sharma M, Sood B. A banana or a syringe: Journey to edible vaccines. J Microbiol Biotechnol 2011;27(3):471-7.

16. Akhilesh T, Anjali K. Edible vaccines: Let thy food be thy medicine. Int J Pharmacol Screen Methods 2014:4:105-8.

17. Lal P, Ramachandran VG, Goyal R, Sharma R. Edible vaccines: Current status and future. Indian J Med Microbiol 2007;25:93-102.

18. Das DK. Plant derived edible vaccines. Curr Trends Biotechnol Pharm 2009:3:113-27.

19. Webster DE, Thomas MC, Strugnell RA, Dry IB, Wesselingh SL. Appetising solutions: An edible vaccine for measles. Med J Aust 2002;176:434-7.

20. Waghulkar, VM. Fruit derived edible vaccines: Natural way for the vaccination. Int J Pharmtech Res 2010;2:2124-7.

21. Singh BD. Biotechnology. $1^{\text {st }}$ ed. India: Kalyani Publishers; 1998.

22. Madhumita N, Deepak V, Pallavi U. Edible vaccines - A review. Int J Pharmacother 2014:4:58-61

23. Krishna C, Jonnala UK, Sri R. Edible vaccines. Sriramachandra J Med 2006;1:33-4.

24. Jacob SS, Cherian S, Sumithra TG, Raina OK, Sankar M. Edible vaccines against veterinary parasitic diseases - Current status and future prospects. Vaccine 2013;31(15):1879-85.

25. Lossl A, Waheed M. Chloroplast-derived vaccines against human diseases: Achievements, challenges and scopes. J Plant Biotechnol 2011:9:527-39. 
26. Swapna LA. Edible vaccines: A new approach for immunization in plant biotechnology. Sch Acad J Pharm 2013;2:227-32.

27. Streatfield SJ. Mucosal immunization using recombinant plant-based oral vaccines. Methods 2006;38(2):150-7.

28. Takahashi I, Nochi T, Kunisawa J, Yuki Y, Kiyono H. The mucosal immune system for secretory $\mathrm{IgA}$ responses and mucosal vaccine development. Inflamm Regen 2010;30:40-7.

29. de Aizpurua HJ, Russell-Jones GJ. Oral vaccination. Identification of classes of proteins that provoke an immune response upon oral feeding. J Exp Med 1988;167(2):440-51.

30. Langridge WH. Edible vaccines. Sci Am 2000;283(6):66-71.

31. Franklin CI, Trieu T, Gonazales RA, Dixon RA. Plant regeneration from seeding explants of green bean (Phaseolus vulgaris L.) via organogenesis. Plant Cell Tissue Organ Cult 1991;24:199-206.

32. De la Riva GA, Gonzalez-Cabrera J, Vasquez R, Ayra-Pardo C. Agrobacterium tumefaciens: A natural tool for plant transformation. Electron J Biotechnol 1998;1:118-32.

33. Lee RW, Strommer J, Hodgins D, Shewen PE, Niu Y. Towards development of an edible vaccine against bovine pneumatic pasteurellosis using transgenic white clover expressing a Mannheimia fusion protein. Infect Immun 2001;69:5786-93.

34. Plantharayil BA. Plant based edible vaccines against poultry diseases: A review. Adv Anim Vet Sci 2014;2:305-11

35. Taylor NJ, Fauquet CM. Microparticle bombardment as a tool in plant science and agricultural biotechnology. DNA Cell Biol 2002;21(12):963-77.

36. Maliga P. Engineering the plastid genome of higher plants. Curr Opin Plant Biol 2002;5(2):164-72

37. Ramshaw IA, Ramsay AJ. The prime-boost strategy: Exciting prospects for improved vaccination. Immunol Today 2000;21(4):163-5.

38. Yoshimatsu K, Kawano N, Kawahara N, Akiyama H, Teshima R, Nishijima M. Current status in the commercialization and application of genetically modified plants and their effects on human and livestock health and phytoremediation. Yakugaku Zasshi 2012;132(5):629-74.

39. Huy NX, Kim SH, Yang MS, Kim TG. Immunogenicity of a neutralizing epitope from porcine epidemic diarrhea virus: $M$ cell targeting ligand fusion protein expressed in transgenic rice calli. Plant Cell Rep 2012;31(10):1933-42.

40. Wang Y, Shen Q, Jiang Y, Song Y, Fang L, Xiao S, et al. Immunogenicity of foot-and-mouth disease virus structural polyprotein P1 expressed in transgenic rice. J Virol Methods 2012;181(1):12-7.

41. Loza-Rubio E, Rojas-Anaya E. Vaccine production in plant systems - An aid to the control of viral diseases in domestic animals: A review. Acta Vet Hung 2010;58(4):511-22.

42. Dauvillée D, Delhaye S, Gruyer S, Slomianny C, Moretz SE, d'Hulst C, et al. Engineering the chloroplast targeted malarial vaccine antigens in Chlamydomonas starch granules. PLoS One 2010;5(12):e15424.

43. Streatfield SJ, Jilka JM, Hood EE, Turner DD, Bailey MR, Mayor JM, et al. Plant-based vaccines: Unique advantages. Vaccine 2001;19(17-19):2742-8.

44. William S. A review of the progression of transgenic plants used to produce plant bodies for human usage. J Young Invest 2002;4:56-61.

45. Renuga G, Tandipani AB, Arur AK. Transgenic banana callus derived recombinant cholera toxin B subunit as potential vaccine. Int J Curr Sci 2014;10:61-8

46. Hire RK, Abhang DR, Ansari FZ, Gangurde AB. A review on edible vaccines. Int J Pharm Res Bio Sci 2012;1:133-44.

47. Doshi V, Rawal H, Mukherjee S. Edible vaccines from GM crops. J Pharm Sci Innov 2013;2:1-6.

48. Rupali RK, Sumit K, Uttam K. Edible vaccine: A prospective substitute for better immunization in future. Int J Pharm Bio Sci 2012;3:948-55.

49. Tiwari S, Verma PC, Singh PK, Tuli R Plants as bioreactors for the production of vaccine antigens. Biotechnol Adv 2009;27:449-67.

50. Parvaiz A. Transgenic plants as green factories for vaccine production. Afr J Biotechnol 2013;12:6147-58.

51. Pant G, Sanjana WK. Edible vaccines: A boon to medical science. Int J Curr Agric Res 2014;3:76-80.

52. Smith ML, Keegan ME, Mason HS, Shuler ML. Factors important in the extraction, stability and in vitro assembly of the hepatitis B surface antigen derived from recombinant plant systems. Biotechnol Prog 2002;18(3):538-50.

53. Castan O' NS, Martin AJ, Marin MS, Alonso P, Parra F, Ordas R. The effect of the promoter on expression of vp60 gene from rabbit hemorrhagic disease virus in potato plants. Plant Sci 2002;162:87-95.

54. Walmsley AM, Arntzen CJ. Plant cell factories and mucosal vaccines. Curr Opin Biotechnol 2003;14:145-50.

55. Singh A, Singh C. A vaccination approach to develop experimental model of Malaria via immunization of mice against Plasmodium yoeli Nigeriensis soluble antigens using qs-21 as adjuvant. Int J Pharm Pharm Sci 2014;6:333-7.

56. Wang L, Goschnick MW, Coppel RL. Oral immunization with a combination of Plasmodium yoelii merozoite surface proteins 1 and $4 / 5$ enhances protection against lethal malaria challenge. Infect Immun 2004;72:6172-5

57. Ajaz M, Vashisht VK, Rizwan R, Susheel S, Jaskanwal S. Edible vaccinevegetables as alternative to needles. Int J Curr Res 2011;33:18-26.

58. Huang Z, Dry I, Webster D, Strugnell R, Wesselingh S. Plant-derived measles virus hemagglutinin protein induces neutralizing antibodies in mice. Vaccine 2001;19:2163-71.

59. Polack FP, Auwaerter PG, Lee SH, Nousari HC, Valsamakis A, Leiferman KM, et al. Production of atypical measles in rhesus macaques: Evidence for disease mediated by immune complex formation and eosinophils in the presence of fusion-inhibiting antibody. Nat Med 1999;5:629-34.

60. Giddings G, Allison G, Brooks D, Carter A. Transgenic plants as factories for biopharmaceuticals. Nat Biotechnol 2000;18:1151-5.

61. Thanavala Y, Yang YF, Lyons P, Mason HS, Arntzen C. Immunogenicity of transgenic plant-derived hepatitis B surface antigen. Proc Natl Acad Sci U S A 1995;92(8):3358-61.

62. Richter LJ, Thanavala Y, Arntzen CJ, Mason HS. Production of hepatitis B surface antigen in transgenic plants for oral immunization. Nat Biotechnol 2000;18(11):1167-71

63. Ma JK, Hiatt A, Hein M, Vine ND, Wang F, Stabila P, et al. Generation and assembly of secretory antibodies in plants. Science 1995;268(5211):716-9.

64. Mason HS, Haq TA, Clements JD, Arntzen CJ. Edible vaccine protects mice against Escherichia coli heat-labile enterotoxin (LT): potatoes expressing a synthetic LT-B gene. Vaccine 1998;16(13):1336-43.

65. Lebens M, Johansson S, Osek J, Lindblad M, Holmgren J. Large-scale production of Vibrio cholerae toxin B subunit for use in oral vaccines. Biotechnology (N Y). 1993;11(13):1574-8.

66. Richter L, Mason HS, Arntzen CJ. Transgenic plants created for oral immunization against diarrheal diseases. J Travel Med 1996;3(1):52-56.

67. Tacket CO, Mason HS, Losonsky G, Clements JD, Levine MM, Arntzen CJ. Immunogenicity in humans of a recombinant bacterial antigen delivered in a transgenic potato. Nat Med 1998;4(5):607-9.

68. Prakash CS. Edible vaccines and antibody producing plants. Biotechnol Dev Monitor 1996;27:10-3

69. Karasev AV, Foulke S, Wellens C, Rich A, Shon KJ, Zwierzynski I, et al. Plant based HIV-1 vaccine candidate: Tat protein produced in spinach. Vaccine 2005;23(15):1875-80.

70. Kim TG, Galloway DR, Langridge WH. Synthesis and assembly of anthrax lethal factor-cholera toxin B-subunit fusion protein in transgenic potato. Mol Biotechnol 2004;28(3):175-83. 